\title{
Mental health literacy about depression among medical students at a tertiary care hospital in South India
}

\author{
Shanti Mohan Kethawath ${ }^{1}$, Srilakshmi Pingali ${ }^{2 *}$, Sai Lakshmi Kante ${ }^{3}$, Umashankar Molangur ${ }^{4}$ \\ ${ }^{1}$ Senior Resident, ${ }^{2}$ Associate Professor, ${ }^{3}$ Junior Resident, ${ }^{4}$ Professor, Dept. of Psychiatry, Gandhi Medical College, Secunderabad, \\ Telanagana, India
}

*Corresponding Author: Srilakshmi Pingali

Email: drpingali@gmail.com

Award Paper: Poduvu Chinnareddy Venkatramamma Award" in Tspsycon 2019

\begin{abstract}
Background: Most of the time, medical students are the first access points to the health care system, and play a critical role in early identification of mental illnesses. Identifying knowledge gaps about mental illness amongst medical students constitutes one of the first step toward reducing treatment gap.

Aims: To assess the level of Mental Health Literacy about depression among medical students.

Methods: A total of 200 medical students, 100 of whom had completed psychiatric posting and 100 who had not completed were recruited through purposive sampling. A semi-structured proforma to capture the socio-demographic details and a self-administered questionnaire containing case vignette about depressive symptoms were administered.

Results: Medical students who have completed their psychiatry posting were significantly better in comparison to those who did not complete psychiatry posting during internship, in terms of identification of depression in the case vignette and recognition of antidepressants as helpful medications for the condition.

Conclusion: Mental health literacy about depression is poor among medical students who have not completed their psychiatric posting.
\end{abstract}

Keywords: Depression; Mental health literacy; Medical students.

\section{Introduction}

Mental illnessess has become an issue of major concern globally. ${ }^{1}$ They are responsible for $13 \%$ of total Disability Adjusted Life Years (DALYs) lost for Years Lived with Disability with depression being the leading cause amongst them. ${ }^{2}$ In developing countries like India, the prevalence of Mental illness is increasing and is becoming one of the major cause for DALYs. In the year, 2017, Mental disorders contributed $4.7 \%(3.7-5.6)$ of the total DALYs compared with $2.5 \%(2 \cdot 0-3 \cdot 1)$ in 1990 and the highest contribution to DALYs due to mental disorders was from depressive disorders $(33 \cdot 8 \%, 29 \cdot 5-38 \cdot 5){ }^{3}$ Currently, the prevalence of depression is estimated to be $5.2 \%$ in individuals older than $18 .{ }^{4}$ However, treatment gap for depression is $85.2 \%$ and ranks second next only to alcohol use disorders which has $86.3 \% .^{5}$ Thus, depression is becoming an important concern among other illnesses.

It has been suggested that up to $70 \%$ of individuals suffering from a mental health disorder do not seek professional help or recognize these disorders in others. ${ }^{5}$ Lack of mental health literacy (MHL) is one of the important factors for delay or lack of help-seeking. The term "mental health literacy" was introduced by Jorm et al. in 1997..$^{6}$ It refers to knowledge and beliefs about mental disorders, which aid in their recognition, management and prevention. Recognizing mental illness, knowing how to find mental health information, knowledge of risk factors and causes, and of the professional help available and attitudes that promote appropriate help seeking are all included in mental health literacy. It was found that mental health literacy is low among general population and non - medical population. ${ }^{7-10}$ However, Mental health literacy among medical professionals is varying.

A cross-sectional survey conducted among psychiatrists and registered nurses in China $(\mathrm{n}=70)$ found that for depression vignette, $100 \%$ of psychiatrists and $87.1 \%$ of registered nurses $(\mathrm{n}=27)$ correctly identified it as depression. ${ }^{11}$ In another study among 1123 non-mental health professionals, less than $60 \%$ could identify the mental disorders correctly. For vignette on depression, 58.1\% doctors could correctly identify it as a depression and 78.2\% quoted that antidepressants could help the condition in the vignettes. ${ }^{12}$ Similarly, in another study, only $35.6 \%$ of medical students $(n=324)$ identified the case vignette as depression. ${ }^{13}$ All these studies indicate that mental health literacy is low, even among medical professionals. In India, studies on mental health literacy are from the general population. Only one study attempted to assess the suicide and depression literacy among students from health care sector. In this study, beliefs about depressive and suicidal symptoms were compared between medical and paramedical students. It was found that depression and suicide literacy is poor among healthcare professional students, particularly among paramedical students. ${ }^{14}$

Thus, from the existing literature it is apparent that not only there is a scarcity of studies among medical professionals, but amongst the studies that have been done, results indicate a low level of MHL. Further, Mental disorders such as depression and anxiety disorders are often nondetected / underdetected among patients attending public health facilities. ${ }^{15}$ Thus, low MHL among medical students leads to lack of detection of mental disorders and delayed 
treatment. This may assume significance as many times medical students are the first access points to the health care system, and play a critical role in early identification of mental illnesses. Therefore, identifying knowledge gaps about depression amongst medical students constitutes one of the first step toward reducing treatment gap. With this background, we aimed to assess the level of MHL among medical students. We further aim to compare mental health literacy about depression among those medical students who had completed their psychiatric posting and those who had not completed.

\section{Materials and Methods}

A cross sectional study design was used. Target population included medical students who completed MBBS and were pursuing their one year internship for the academic year 2019-2020. A total of 100 medical students who had completed their psychiatric posting and 100 medical students who had not completed psychiatric posting were included in the study. Those students who were posted in Psychiatry department as a part of their rotating internship were excluded from the study. Medical students were ensured of the confidentiality of the information provided. They were individually approached and recruited after obtaining written informed consent. After obtaining the sociodemographic profile, participants were administered a Mental Health Literacy questionnaire for depression adopted with permission from Jorm et al., 1997. ${ }^{6}$ It consists of case vignette describing people experiencing symptoms of depression. Subsequently, questions about the case vignette involving a mixture of open and closed responses regarding the name of the problem, its causes and risk factors, discrimination and stigmatization, the helpfulness of possible service providers, treatments, prognosis and experiences were asked. More than one response was possible for each item. In order to maintain a cultural and regional cohesiveness, the name given in the vignette (Johny) was changed to a more relatable name in the Indian setting (Ramu). Some of the questions which were irrelevant to the Indian culture were removed. Approval to conduct the study was obtained from ethics committee before commencement of the study.

\section{Statistical analysis}

Data were analyzed with IBM-SPSS 26.0 software (IBM Corp., Armonk, NY, USA) Descriptive statistics were used to tabulate socio-demographic characteristics of the sample. Descriptive statistics were also used to calculate the percentage of each endorsed statement. Chi-square test $\left(\chi^{2}\right.$ tests) for categorical variables was used to compare the recognition, intervention beliefs, and other appropriate domains from the case vignette between medical students who had completed their psychiatric posting and those who had not. Level of statistical significance was kept at $p<0.05$ and all the tests were two tailed.

\section{Results}

Sample characteristics
Sociodemographic details of the participants have been given in Table $1.66 .5 \%$ of the participants were females. Mean age of the medical students was $23.43 \pm 0.69$ years. Majority (91\%) of the students were from urban background. $62.5 \%$ of the students did their MBBS from government medical college and the rest $37.5 \%$ completed their MBBS from private medical college and were doing their internship in the current government medical college.

Table 1: Sociodemographic details of the participants $(\mathrm{n}=200)$

\begin{tabular}{|c|c|c|}
\hline Variable & Total (n) & $\begin{array}{c}\text { Percentage } \\
(\%)\end{array}$ \\
\hline Male & 67 & 33.5 \\
\hline Female & 133 & 66.5 \\
\hline Urban & 182 & 91.0 \\
\hline Rural & 18 & 9.0 \\
\hline Hindu & 180 & 90.0 \\
\hline Muslim & 9 & 4.5 \\
\hline Sikh & 2 & 1.0 \\
\hline Christian & 9 & 4.5 \\
\hline $\begin{array}{l}\text { MBBS from government } \\
\text { hospital }\end{array}$ & 125 & 62.5 \\
\hline $\begin{array}{l}\text { MBBS from private } \\
\text { hospital }\end{array}$ & 75 & 37.5 \\
\hline
\end{tabular}

\section{Recognition of illness}

Table 2 shows the frequency distribution of identification of illness categories, based on the case vignette. Depression was correctly identified by $170(85 \%)$ medical students. More than half of the participants identified the given vignette as having more than one problem. $12(6 \%)$ medical students wrongly identified the case vignette as having schizophrenia/ psychosis.

Table 2: Frequency distribution of identification of illness based on case vignette

\begin{tabular}{|l|c|c|}
\hline Variable & $\begin{array}{c}\text { Total } \\
(\mathbf{n})\end{array}$ & $\begin{array}{c}\text { Percentage } \\
(\mathbf{\%})\end{array}$ \\
\hline Depression & 170 & 85 \\
\hline Schizophrenia/Psychosis & 12 & 6.0 \\
\hline Mental illness & 40 & 20 \\
\hline Stress & 74 & 37 \\
\hline Nervous breakdown & 19 & 9.5 \\
\hline $\begin{array}{l}\text { Psychological/Mental/emotional } \\
\text { problems }\end{array}$ & 85 & 42.5 \\
\hline Multiple illness identified & 122 & 61 \\
\hline
\end{tabular}

\section{Intended actions to seek help and intentions about first aid}

Table 3 shows the frequency distribution of participant's response to question related to intention of seeking help and intentions about first aid. 76\% of participants reported they would go for help if they had a problem similar to that described in the given case vignette. A majority $(91.5 \%)$ of the participants said that they would help, if they came to know anyone who is suffering from such a problem. 
Table 3: Frequency distribution of participant's response to questions related to intended actions to seek help and intentions about first aid

\begin{tabular}{|l|c|c|}
\hline Variable & $\begin{array}{c}\text { Total } \\
(\mathbf{n})\end{array}$ & $\begin{array}{c}\text { Percentage } \\
(\%)\end{array}$ \\
\hline $\begin{array}{l}\text { Q. If you had a problem like Ramu, would you go for } \\
\text { help }\end{array}$ & 153 & 76.5 \\
\hline Yes & 28 & 14.0 \\
No & 19 & 9.5 \\
\hline Don't know/Don't want to answer & . Imagine Ramu is someone you have known for a long \\
\hline Qime and care about. What would you do? \\
\hline Help him & 183 & 91.5 \\
Don't help him & 5 & 2.5 \\
Don't know/Don't want to answer & 12 & 6.0 \\
\hline
\end{tabular}

\section{Beliefs about interventions}

Table 4. illustrates the frequency distribution of participant's response to question on beliefs of various people and interventions that could help Ramu (from case vignette). $179(89.5 \%)$ medical students agreed that a psychiatrist could help the person in the vignette. A psychologist was considered as helpful by $36.5 \%$ of medical students. $154 \quad(77 \%)$ medical students identified antidepressants to be helpful followed by Vitamins (27.5\%), antipsychotics (14\%) and Sleeping pills (10.5\%). Cutting down the use of substances like cannabis/alcohol/cigarette was identified as helpful by $31 \%$ whereas, $7 \%$ agreed to use these substances as a means of relaxation.

Table 4: Frequency distribution of participant's response to question on beliefs about interventions $(n=200)$

\begin{tabular}{|l|c|c|}
\hline Variable & $\begin{array}{c}\text { Total } \\
\text { (n) }\end{array}$ & $\begin{array}{c}\text { Percentage } \\
\text { (\%) }\end{array}$ \\
\hline Persons that are likely to be helpful \\
\hline $\begin{array}{l}\text { Multiple options (General } \\
\text { physician, Lecturer, Counsellor, }\end{array}$ & 179 & 89.5 \\
$\begin{array}{l}\text { Psychologist, Psychiatrist, Family } \\
\text { member, Close friend }\end{array}$ & \\
\hline Psychologist & 73 & 36.5 \\
\hline Psychiatrist & 167 & 83.5 \\
\hline Medicines that are likely to be helpful \\
\hline $\begin{array}{l}\text { Multiple options (Vitamins, } \\
\text { Antidepressants, } \\
\text { Antipsychotics, Sleeping pills) }\end{array}$ & 33 \\
\hline
\end{tabular}

\begin{tabular}{|l|c|c|}
\hline Antidepressants & 154 & 77 \\
\hline Antipsychotics & 28 & 14 \\
\hline Vitamins & 55 & 27.5 \\
\hline Sleeping pills on use of alcohol/ & 21 & 10.5 \\
\hline $\begin{array}{l}\text { Cutting down on } \\
\text { smoking/cannabis }\end{array}$ & 62 & 31 \\
\hline $\begin{array}{l}\text { Using alcohol/smoking } \\
\text { cigarettes/cannabis to relax }\end{array}$ & 14 & 7 \\
\hline
\end{tabular}

\section{Exposure to mental disorders}

Table 5 shows the frequency of participants or their family / close friends being exposed to mental disorders. 39\% of participants reported that someone in their family or close circle of friends had suffered from a problem similar to that described in case vignette. 44 (22\%) participants quoted that they had a problem similar to case vignette (Ramu), however, only $25 \%$ of these participants said that they received professional help or treatment for these problems.

Table 5: Frequency distribution of response to questions related to exposure to mental disorders

\begin{tabular}{|l|c|c|}
\hline Variable & Total (n) & Percentage(\%) \\
\hline $\begin{array}{l}\text { Has anyone in your family/ } \\
\text { close circle of friends ever had } \\
\text { a problem similar to Ramu }\end{array}$ & 78 & 39.0 \\
\hline $\begin{array}{l}\text { Have you ever had a problem } \\
\text { similar to Ramu's }\end{array}$ & 44 & 22.0 \\
\hline $\begin{array}{l}\text { Have you received any } \\
\text { professional help or treatment } \\
\text { for these problems }\end{array}$ & 11 & 25.0 \\
\hline
\end{tabular}

\section{Recognition of illness between medical students who} completed psychiatry posting and those who did not

Table 6. illustrates the comparison of responses based on whether participants had completed their psychiatry posting or not. The participants who completed their psychiatry posting were significantly able to correctly identify the vignette as depression compared to those who did not complete the posting $(\mathrm{P}=0.017)$. Similarly, participants who had completed their psychiatry posting were significantly able to identify antidepressants as helpful compared to those who did not complete the posting $(\mathrm{P}=0.019)$. In all other domains no significant difference was found between the two group of participants.

Table 6: Illustrates the distribution of recognition of illness and beliefs about intervention based on completion of psychiatry posting

\begin{tabular}{|l|c|c|c|}
\hline Recognition of illness & $\begin{array}{c}\text { Psychiatry posting not } \\
\text { completed }\end{array}$ & $\begin{array}{c}\text { Psychiatry posting } \\
\text { completed }\end{array}$ & Chi square value $\boldsymbol{\chi 2}$ (p value) \\
\hline Recognition of illness & 79 & 91 & $5.647\left(0.017^{*}\right)$ \\
\hline Depression & 12 & 7 & $1.454(0.228)$ \\
\hline Schizophrenia & 70 & 84 & $5.534\left(0.019^{*}\right)$ \\
\hline Recognition of medications to be useful & 12 & $0.664(0.415)$ \\
\hline Antidepressants & 16 & & \\
\hline Antipsychotics & \multicolumn{5}{|l}{} \\
\hline
\end{tabular}

*significant at less than 0.05 


\section{Discussion}

Only one other study had assessed the mental health literacy among medical students from Indian context. ${ }^{14}$ In their study, illness related domains were explored but they did not explore the identification of the illness. In our study, we explored the illness domains as well as identification of the illness.

In the current study, Depression was correctly identified by $85 \%$ of medical students. Illness identification rate in our study was high when compared to that by Sayarifard et al., $2014^{13}$ and $\mathrm{Wu}$ et al., 2017, ${ }^{12}$ but low when compared to study by Liu et al., 2011. ${ }^{11}$ This difference in finding in comparison to Sayarifard et al., $2014^{13}$ could be explained on the basis of inclusion of more than half of the participants from paramedical field in that study. This is unlike our study where we have included exclusively medical students. Higher identification rate in our study compared to that by Wu et al., $2017^{12}$ might be due to $50 \%$ of the participants in our study have completed their psychiatry posting in the six months prior to this study, thus they might be better in identifying the illness. Similarly, high identification rate in a study by Liu et al., $2011^{11}$ can be understood as more than half of the participants were psychiatrists.

In our study, $89.5 \%$ of medical students agreed that a psychiatrist could help the person in the vignette in line with some of the previous studies. ${ }^{11,12}$ Similarly, $77 \%$ of medical students identified antidepressants to be helpful much similar to other studies. ${ }^{11,12}$ Contrarily, another study found that antidepressants were identified as helpful only by $39.5 \% .^{16}$ However, in their study, half of the participants were nursing students which are not adequately exposed about mental health compared to that of medical students.

In the question "Have you ever had a problem similar to Ramu's," which assesses exposure to mental disorders, $22 \%$ of the medical students responded "yes," and out of then only $25 \%$ reported that they received any professional help or treatment for these problems. This has noteworthy considerations, as in a country like India, where the treatment gap for major depressive disorder is 85.2 percent as per National Mental Health Survey, 2016. ${ }^{4}$ Thus, even in the medical student's, help seeking for depression is quite low. Though, we didn't further evaluate for possible causes, low intention of seeking help among medical students urges the need to identify and resolve the barriers in seeking help.

In the current study, the participants who completed their psychiatry posting were significantly able to correctly identify the vignette as depression $(\mathrm{P}=0.017)$ and able to identify antidepressants as helpful compared to those who did not complete the posting $(\mathrm{P}=0.019)$. It can be explained as the medical students in the current medical college during 15 days of psychiatry posting, apart from being exposed to clinical material, have to mandatorily attend and present seminars about relevant clinical topics. ${ }^{17}$ This, might have resulted in a better understanding about mental health conditions. Medical Council of India has recommended that all undergraduate students must receive two weeks clinical posting and 20 lectures in psychiatry in the fifth semester and assessment in the form of short notes in paper two of General Medicine. ${ }^{18}$ However, its strict implementation is doubtful. It has noteworthy implications. Unless mental health literacy is incorporated strictly from the undergraduate level, the knowledge about mental illness will continue to be poor in future doctors. This is also important as most patients with psychiatric disorders seek help from non-psychiatry physicians and general practitioners. ${ }^{17}$ Thus, many times medical students are the first access points to the health care system, and play a critical role in early identification of mental illnesses. Further, it has been found that the willingness to approach a psychiatrist is much more if the patient is referred by a primary health-care physician, further reiterating the need for training in psychiatry at the undergraduate and internship level. ${ }^{19} \mathrm{~A}$ high level of MHL about depression thus would make early identification of depression and referral to mental health specialists more likely, which could help reduce the burden of the depression. We assume that high level of MHL about depression in medical students who completed their psychiatric posting might be due to mandatory seminar presentations made by these students, which might have added to their clinical knowledge. Hence, we propose the introduction of a mandatory seminar presentation focusing on relevant clinical topics in this group of students.

\section{Limitations}

Our study has some limitations which need to be mentioned. We didn't compare MHL among those who presented seminar on relevant clinical topics and those who didn't. This could have further strengthened the need for mandatory seminars during internship. Current medical students are from a single hospital, which runs the risk of bias in a heterogeneous population. Therefore, it is difficult to generalize the study results to a broader mental health professional population. Another limitation is the instrument used. The questionnaire is limited by providing multiple options for diagnosis, which might prevent the participants from drawing clear conclusions about diagnosis. Further, the questionnaire though is self-administered in English language, it was not validated to the Indian population. Future research is needed to compare MHL about depression from different medical colleges in this medical population using validated questionnaires.

\section{Conclusion}

The study showed mental health literacy is poor among medical students who have not completed their psychiatric posting. Low mental health literacy in medical students especially those who have not completed their psychiatry posting prompts the need for a strict implementation of undergraduate teaching schedule. Implementation of mandatory seminars during psychiatry internship may be one means of improving the mental health literacy. 


\section{Acknowledgement}

We thank all the medical students pursuing their internship for the year 2019-2020 for their active participation in the study.

\section{Source of Funding}

Nil.

\section{Conflicts of Interest}

None

\section{References}

1. Reddy V, Gupta A, Lohiya A, Kharya P. Mental Health Issues and Challenges in India: A review. Int J Sci Res Publ. 2013;3(2):3.

2. Hay SI, Abajobir AA, Abate KH, Abbafati C, Abbas KM, Abd-Allah F, et al. Global, regional, and national disabilityadjusted life-years (DALYs) for 333 diseases and injuries and healthy life expectancy (HALE) for 195 countries and territories, 1990-2016: A systematic analysis for the Global Burden of Disease Study 2016. Lancet. 2017;390(10100):1260-3445.

3. Sagar R, Dandona R, Gururaj G, Dhaliwal RS, Singh A, Ferrari A, et al. The burden of mental disorders across the states of India: the Global Burden of Disease Study 19902017. Lancet Psychiatry. 2019;7(2):148-61.

4. Gururaj G, Varghese M, Benegal V, Rao GN, Pathak K, Singh LK, et al. National Mental Health Survey of India, 2015-16: prevalence, patterns and outcomes. Bengaluru: National Institute of Mental Health and Neuro Sciences, NIMHANS Publication. 2016;1294.

5. Farrer L, Leach L, Griffiths KM, Christensen H, Jorm AF. Age differences in mental health literacy. BMC Public Health. $2008 ; 20 ; 8: 125$.

6. Jorm AF, Korten AE, Jacomb PA, Christensen H, Rodgers B, Pollitt P. "Mental health literacy": a survey of the public's ability to recognise mental disorders and their beliefs about the effectiveness of treatment. Med J Aust. 1997;166(4):182-6.

7. Ogorchukwu JM, Sekaran VC, Sreekumaran Nair LA. Mental health literacy among late adolescents in South India: What they know and what attitudes drive them. Indian J Psychol Med. 2016;38(3):234.

8. Saraf G, Chandra PS, Desai G, Rao GN. What adolescent girls know about mental health: findings from a mental health literacy survey from an urban slum setting in India. Indian $J$ Psychol Med. 2018;40(5):433.

9. Venkataraman S, Patil R, Balasundaram S. Why mental health literacy still matters: A review. Int J Community Mede Public Health. 2019;6(6):27239.

10. Aluh DO, Okonta MJ, Odili VU. Cross-sectional survey of mental health literacy among undergraduate students of the University of Nigeria. BMJ Open. 2019;9(9):e028913.

11. Liu W, Gerdtz MF, Liu TQ. A survey of psychiatrists' and registered nurses' levels of mental health literacy in a Chinese general hospital: Mental health literacy survey. Int Nurs Rev. 2011;58(3):361-9.

12. Wu Q, Luo X, Chen S, Qi C, Long J, Xiong Y, et al. Mental health literacy survey of non-mental health professionals in six general hospitals in Hunan Province of China. PLOS ONE. 2017;12(7).

13. Sayarifard A, Ghadirian L, Mohit A, Eftekhar M, Badpa M, Rajabi F. Assessing mental health literacy: What medical sciences students' know about depression. Med J Islam Repub Iran. 2015;29:161.

14. Ram D, Chandran S, H B. Suicide and depression literacy among health professions students in tertiary care centre in South India. J Mood Disord. 2017;1.

15. Kagee A, Tsai AC, Lund C, Tomlinson M. Screening for common mental disorders in low resource settings: reasons for caution and a way forward. Int Health. 2013;5(1):11-4.

16. Picco L, Seow E, Chua BY, Mahendran R, Verma S, Chong SA, et al. Recognition of mental disorders: findings from a cross-sectional study among medical students in Singapore. BMJ Open. 2017;7(120):e019038.

17. Pingali S. Interns' posting in psychiatry-A window of opportunity. Telangana J Psychiatry. 2018:4(1):1-2.

18. Manohari SM, Johnson PR, Galgali RB. How to teach psychiatry to medical undergraduates in India?: A model. Indian J Psychol Med. 2013;35(1):23.

19. Srinivasan K, Babu RK, Appaya P, Subrahmanyam HS. A study of inpatient referral patterns to a general hospital psychiatry unit in India. Gen Hosp Psychiatry. 1987;9(5):3725 .

How to cite this article: Kethawath SM, Pingali S, Kante SL, Molangur U. Mental health literacy about depression among medical students at a tertiary care hospital in South India. Telangana J Psychiatry. 2020;6(1):9-13. 